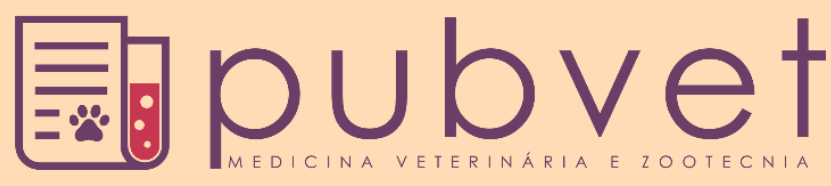

https://doi.org/10.31533/pubvet.v15n04a793.1-7

\title{
Análise da produção de leite de cabras Saanen
}

\author{
Vinicius Brack Gestaro $^{19}$, João Feliz Duarte de Moraes ${ }^{2 \oplus \mathbb{Q}}$, Verônica Schmidt ${ }^{3 *}$ \\ ${ }^{I}$ Mestrando da Universidade Federal do Rio Grande do Sul, Programa de Pós-graduação em Agronegócios, Porto Alegre, RS, Brasil. \\ ${ }^{2}$ Professor da Universidade Federal do Rio Grande do Sul, Departamento de Estatística. Porto Alegre -RS Brasil. \\ ${ }^{3}$ Professora da Universidade Federal do Rio Grande do Sul, Departamento de Medicina Veterinária Preventiva, Porto Alegre, RS, Brasil. \\ *Autor para correspondência, E-mail: veronica.schmidt@ufrgs.br
}

\begin{abstract}
Resumo. A cadeia produtiva de leite de cabra no estado do Rio Grande do Sul ainda é pouco desenvolvida, devido principalmente, a hábitos culturais e o preconceito quanto aos produtos elaborados com leite de cabra. Além disso, os caprinos ainda são vistos como animais com baixas necessidades nutricionais e sanitárias, sendo criados, muitas vezes, em áreas não apropriadas. No presente estudo realizou-se uma análise de dados secundários, provenientes de uma unidade produtiva de leite de cabra localizada em São Francisco de Paula-RS. Os dados referem-se ao volume semanal de produção leiteira, conforme a ordem de partos, no período de 2006 a 2017. Com base nestes dados, construiu-se a curva de produção no decorrer de cinco lactações. Identificou-se que a curva mantém uma tendência cúbica padrão em relação ao tempo de lactação, independentemente da ordem de parto. Contudo, o volume de leite produzido aumenta gradativamente até a terceira lactação, a partir da qual volta a diminuir.
\end{abstract}

Palavras-chave: Cadeia produtiva, curva de lactação, lactação

\section{Saanen goat milk production analysis}

Abstract. The goat milk productive market in the state of Rio Grande do Sul is little developed yet due, especially, to cultural habits and prejudice with products done with goat milk. Beyond, goats still known as animals with low nutritional requirements and sanitary conditions raised, most of the time, in inappropriate areas. Secondary data analysis was done, obtained from a milk goat productive farm located in São Francisco de Paula-RS. Data represents the volume of milk produced weekly, according to the parturition order, in the period from 2006 to 2017. Based on this data, the production curve of five years was created. It was determined that the curve keeps a standard cubic tendency in relation to the lactation period. Yet, the volume of milk produced increases gradually until the third lactation, after that it starts to decrease.

Keywords: Productive chain, lactation curve, lactation

\section{Análisis de la producción de leche de cabra Saanen}

Resumen: La cadena de producción de leche de cabra en el estado de Rio Grande do Sul aún se encuentra poco desarrollada, principalmente debido a los hábitos culturales y los prejuicios sobre los productos elaborados con leche de cabra. Además, las cabras todavía se consideran animales con escasas necesidades nutricionales y sanitarias y, a menudo, se crían en zonas inapropiadas. En el presente estudio se realizó un análisis de datos secundarios de una unidad de producción de leche de cabra ubicada en São Francisco de Paula-RS. Los datos se refieren al volumen semanal de producción de leche, según el orden de nacimiento, de 2006 a 2017. Con base en estos datos, se construyó la curva de producción durante cinco lactancias. Se identificó que la curva mantiene una tendencia 
cúbica estándar en relación con el tiempo de lactancia, independientemente del orden de parto. Sin embargo, el volumen de leche producida aumenta gradualmente hasta la tercera lactancia, después de lo cual vuelve a disminuir.

Palabras clave: Cadena de producción, curva de lactancia, lactancia

\section{Introdução}

Os caprinos possuem características que contribuem para sua permanência e distribuição em amplas regiões do mundo e, entre esta rusticidade, prolificidade e adaptabilidade, as quais tornam esta espécie capaz de habitar regiões áridas ou úmidas, frias ou quentes, planas ou montanhosas.

A espécie caprina é responsável por aproximadamente $2 \%$ do suprimento anual de leite do mundo. Entretanto, sua contribuição econômica é notória, tanto em países desenvolvidos como em desenvolvimento. O maior contingente de caprinos se encontra na Ásia, África e América Latina, onde a Ásia responde pela maior parcela do rebanho, com aproximadamente $60 \%$ do total de cabeças.

A cadeia produtiva de leite de cabra no estado do Rio Grande do Sul ainda é pouco desenvolvida, devido principalmente, a hábitos culturais, especialmente o preconceito quanto aos produtos elaborados com leite de cabra. Além disso, os caprinos ainda são vistos como animais com baixas necessidades nutricionais e sanitárias sendo criados, muitas vezes, em áreas não apropriadas. Contudo, os caprinos têm alta capacidade produtiva necessitando para expressar seu potencial, condições de produção mínimas como sanidade e alimento. A capacidade do caprino de adaptação e seleção dos alimentos, é um fator a ser melhor explorado para a produção de leite em escala. Isto por que, as características deste produto (alta digestibilidade, flavor, entre outras) possuem um grande nicho de mercado que necessita investimento para fortalecimento da produção de leite de cabra.

Para tanto, conhecer as peculiaridades da produção de leite nas fêmeas caprinas é um fator importante para o fortalecimento desta cadeia produtiva. Neste sentido, o presente estudo analisou os dados de produção leiteira de cabras Saanen de uma unidade produtiva no Rio Grande do Sul, através da construção da curva de lactação deste rebanho.

\section{Material e métodos}

Realizou-se um estudo descritivo e exploratório em uma Unidade Produtiva (UP) de leite de cabra. O estudo é descritivo, pois apresenta como objetivo a descrição das características de determinada população ou fenômeno ou, então, o estabelecimento de relações entre variáveis. Exploratório, pois visa proporcionar maior familiaridade com o problema buscando torná-lo mais explícito, sendo realizada quando o tema é pouco explorado (Gil, 2008).

O delineamento deste estudo consiste em uma pesquisa documental, a qual vale-se de documentos que ainda não receberam tratamento analítico e ainda podem ser reelaborados de acordo com a pesquisa (Gil, 2008). Para tanto, utilizaram-se dados secundários referentes a um banco de anotações da UP, no período de 2006 a 2017. O banco de dados era composto pelo histórico dos indivíduos, produções diárias, ordem e estação do parto.

A UP está localizada no município de São Francisco de Paula (Localização: 29² 26' 52' S 50 35' 02' O), na região dos Campos de Cima da Serra, Rio Grande do Sul. O município possui mais de 21 mil habitantes e destes, $37 \%$ vivem em áreas rurais; a localidade tem $3.274 \mathrm{~km}^{2}$ de área e está a 970 metros de altitude, com clima subtropical (Prefeitura Municipal, 2020)

O sistema de produção era semi-confinamento, onde os animais pernoitavam no galpão, recebiam uma porção de ração e, conforme a época do ano, um complemento com pasto cultivado (Avena sativa e Lolium multiflorum) no inverno, devido à redução do volume de pastagens. No decorrer do dia, as cabras permaneciam em piquetes de campo nativo, realizando rodízio destes conforme a altura das pastagens; cada piquete possuía uma diversidade de forrageiras, variando oferta e qualidade.

O produtor não tinha controle de qual forragem cada indivíduo consumia e quantidade das forragens ofertadas nos piquetes, sendo que cada indivíduo selecionava o que iria consumir. Conforme a estação do ano em que se encontrava, havia diversidade das forrageiras de inverno ou de verão. 
Quanto ao manejo reprodutivo do plantel, as fêmeas nascidas eram criadas com amamentação artificial, com sucedâneo (leite bovino em pó), até atingirem $12 \mathrm{~kg}$ de peso vivo quando ocorria o desmame; a recria era realizada até as cabritas atingirem $35 \mathrm{~kg}$, quando eram colocadas em reprodução.

A reprodução do plantel ocorria em duas temporadas, para haver maior distribuição de volume de leite ao longo do ano. As fêmeas eram cobertas em apenas uma determinada estação e, quando não resultasse em prenhes positiva, esta era realocada na temporada seguinte; caso nesta segunda temporada ainda não apresentasse prenhez era, então, descartada do plantel.

Semanalmente, o produtor realizou a mensuração do volume individual de leite produzido por 182 fêmeas, até cinco lactações, e os dados foram tabulados em planilha Excel $^{\circledR}$. Realizou-se análise descritiva do total de dados tabulados (362 lactações) e, para a análise estatística, os outliers (lactações interrompidas, animais vendidos, entre outros) foram retirados resultando em 317 lactações de cabras Saanen (Tabela 1).

Tabela 1. Número de observações (lactações), segundo a ordem de parto.

\begin{tabular}{lcc}
\hline Ordem de parto & Observações & Porcentagem \\
\hline 1 & 97 & 30,6 \\
2 & 86 & 27,1 \\
3 & 72 & 22,7 \\
4 & 43 & 13,6 \\
5 & 19 & 6,0 \\
\hline Total & 317 & 100,0 \\
\hline
\end{tabular}

Os dados foram analisados por meio de uma ANOVA com medidas repetidas. Determinou-se as médias de produção leiteira, em cada lactação e organizaram-se quatro intervalos entre as semanas de lactação ( $\mathrm{S} 1=1$ a 7 semanas; $\mathrm{S} 8=8$ a 17 semanas; $\mathrm{S} 18=18$ a 27 semanas e $\mathrm{S} 28 \geq 28$ semanas de lactação - variável independente, tempo) utilizando-se o teste de Mauchly; as comparações entre estas foi realizada pelo teste de Bonferroni, ao nível de significância de 0,05 (5\%), utilizando o software SPSS versão 18.

\section{Resultados e discussão}

Verificou-se que a produção média diária de leite foi superior a um litro até a $42^{\mathrm{a}}$ semana pós-parto (294 dias), nas cinco lactações. Sendo que o volume total médio do plantel neste período é apresentado na Tabela 2.

Quando considerados os indivíduos que atingiram uma persistência mínima de 37 semanas de lactação (período S28), correspondendo à 240 lactações, os volumes médios diários e totais foram superiores à produção do total de indivíduos com até 42 semanas de lactação (total do plantel = 317 lactações) (Tabela 2). Esta diferença resultou na produção total de 37 a 102 litros de leite a mais, conforme a lactação.

Tabela 2. Produção média de leite (L) em cada lactação de acordo com o tempo de persistência (semanas).

\begin{tabular}{|c|c|c|c|c|c|c|}
\hline \multirow{2}{*}{$\begin{array}{l}\text { Persistência de lactação } \\
\text { (semanas) }\end{array}$} & \multirow{2}{*}{ Parâmetro } & \multicolumn{5}{|c|}{ Lactação } \\
\hline & & 1 & 2 & 3 & 4 & 5 \\
\hline \multirow{2}{*}{37} & Total & 622,00 & 703,39 & 749,25 & 731,22 & 738,63 \\
\hline & Diária & 2,11 & 2,39 & 2,55 & 2,49 & 2,51 \\
\hline \multirow{2}{*}{$\leq 42$} & Total & 584,73 & 621,62 & 707,44 & 651,07 & 636,48 \\
\hline & Diária & 1,99 & 2,11 & 2,40 & 2,21 & 2,16 \\
\hline
\end{tabular}

Na Bahia, cabras da raça Alpina apresentaram duração média de lactação de cerca de $192 \pm 21$ e 220 \pm 28 dias (27 e 31 semanas) na primeira e segunda lactação, respectivamente (Santos \& Santana, 2011). A duração menor no tempo de lactação pode ser decorrente de fatores ambientais, manejo ou seleção do plantel.

Semelhante ao observado no presente estudo, a produção leiteira média diária de cabras Saanen no DF foi determinada em 2,34 \pm 0,63 kg (Soares Filho et al., 2001), e em 2,14 e 2,27 L na $1^{\mathrm{a}}$ e $2^{\mathrm{a}}$ lactação, respectivamente, em cabras Alpinas na Bahia (Santos \& Santana, 2011). 
Fato a ser ressaltado entre os animais do plantel estudado, é uma cabra de primeira ordem de parto que produziu leite por 123 semanas, totalizando 3.250 litros de leite no período (produção média diária de 3,76 L). Durante este período, esta fêmea não gestou, corroborando as afirmações de que a duração da lactação está estreitamente relacionada à produção de leite e define a forma da curva de lactação (Fonseca, 2014), sendo que a persistência prolongada resulta em diminuição na eficiência reprodutiva do animal ao longo de sua vida produtiva.

O aumento significativo na duração da lactação é favorável e preferível em relação ao aumento da produção de leite diária, pois cabras que produzem mais leite por dia têm maior tendência a terem mastite e têm maiores necessidades nutricionais (Santos \& Santana, 2011).

Ao se analisar os dados referentes ao número total de lactações observadas no período, independentemente da estação do ano e estro natural ou induzido, verificou-se que a curva de lactação manteve uma mesma tendência, independente da ordem de parto. O modelo que melhor representa a rrelação entre tempo de lactação e volume de leite produzido é a equação cúbica (Figura 1).

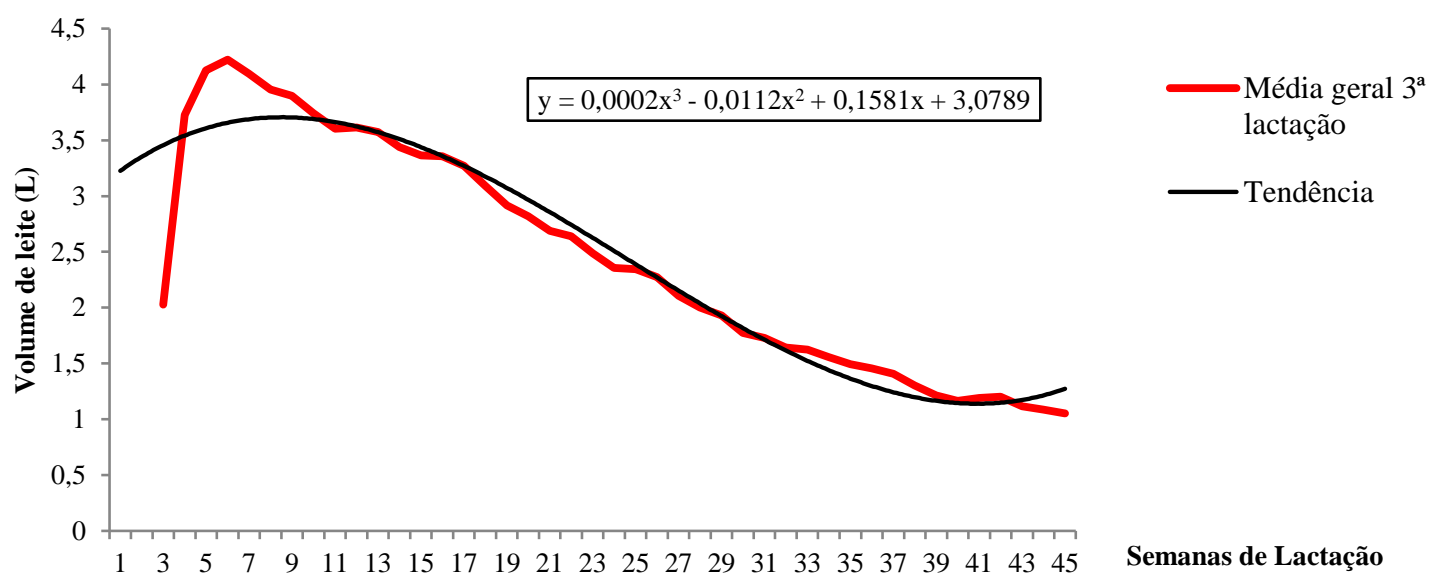

Figura 1. Equação cúbica, ilustrando a tendência da curva de lactação na sequência dos partos.

Contudo, quando se compararam as médias de produção leiteira em cada lactação, verificou-se diferença significativa da primeira lactação com a terceira $(\mathrm{P}<0,001)$ e quarta $(\mathrm{P}=0,028)$ lactações (Figura 2), representando $121 \mathrm{~L}$ e $93 \mathrm{~L}$ de leite a mais na terceira e quarta lactação, respectivamente.

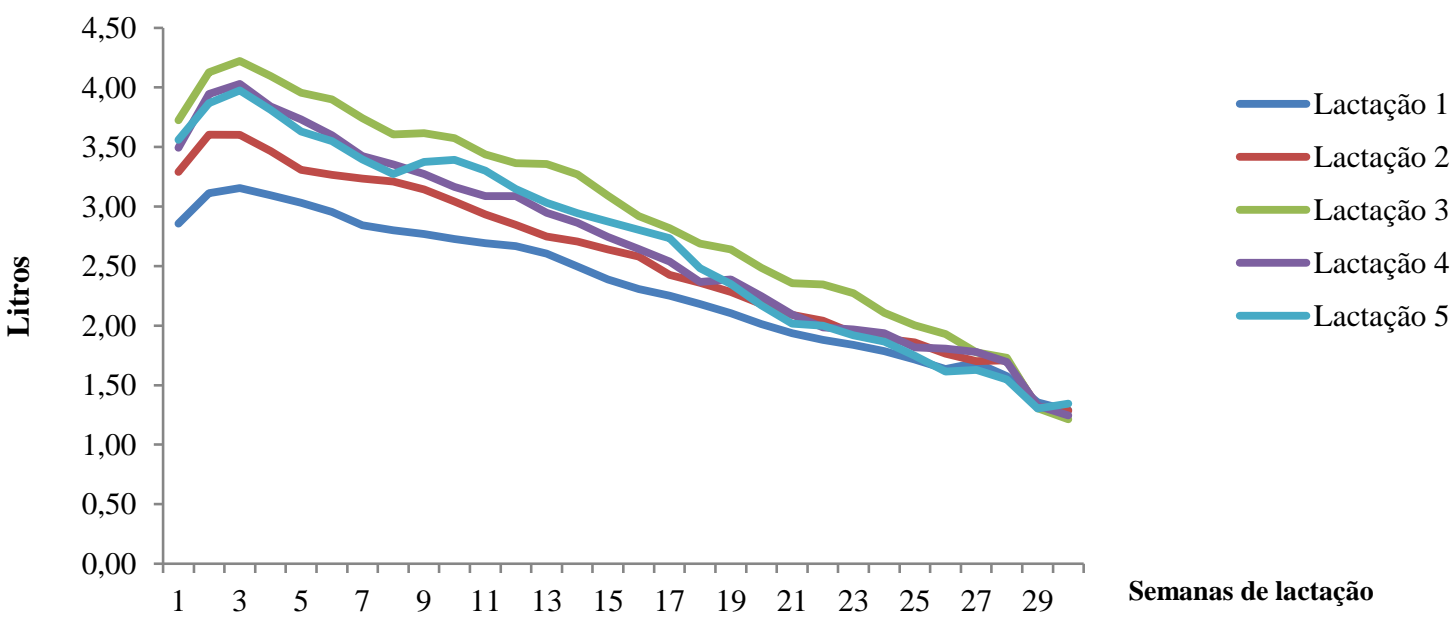

Figura 2. Tendência da curva de lactação (volume de leite produzido) em cabras Saanen, segundo a semana de lactação e a ordem de parto (lactação).

As maiores produções leiteiras são alcançadas entre a $3^{\text {a }}$ e $4^{\mathrm{a}}$ lactação (Sotillo \& Méndez, 1994), a partir da qual se verifica tendência à diminuição na produção leiteira diária. Embora já tenha sido verificado que a ordem de parto não teve efeito $(\mathrm{P}>0,05)$ sobre a produção de leite e a duração de lactação (Carneiro et al., 2017), isto por que a fisiologia da glândula mamária em todas espécies leiteiras, 
possui um incremento progressivo na capacidade de produção de leite ao longo das sucessivas lactações. Este comportamento se deve ao desenvolvimento dos alvéolos nas lactações subsequentes, sem que haja involução dos alvéolos já desenvolvidos nas lactações anteriores. Nesse sentido, entende-se que as cabras Saanen analisadas alcançaram a máxima maturidade fisiológica do sistema mamário na terceira ordem de parto, atingindo a maior produção entre as lactações.

Em um estudo analisando 106 cabras (39 Saanen, 6 Toggenburg e 61 mestiças) agrupadas em categorias pela ordem de parto (primíparas e pluríparas) e estágio de lactação (inicial - 0 a 30 dias, pico - 30 a 45 dias e pós-pico -mais de 45 dias) (Rangel et al., 2012), foi verificado que as cabras pluríparas apresentaram maiores médias de produção no início $(4,41 \mathrm{~kg} / \mathrm{dia})$ e no pico $(5,42 \mathrm{~kg} / \mathrm{dia})$ de lactação.

Considerando-se a produção leiteira em cada semana, verificou-se homogeneidade entre períodos ocorrendo, contudo, variabilidade na produção leiteira entre estes. Desta forma, os dados semanais foram organizados e analisados em períodos ( $\mathrm{S} 1, \mathrm{~S} 8, \mathrm{~S} 18$ e S28). Contudo, quando se compararam os períodos de lactação entre as ordens de parto, determinou-se diferença significativa $(\mathrm{P}=0,033)$ para $\mathrm{S} 1$ entre a primeira e a terceira ordem de parto. Para $\mathrm{S} 8$, houve diferença significativa da primeira ordem de parto com segunda $(\mathrm{P}=0,011)$, terceira $(\mathrm{P}<0,001)$, quarta $(\mathrm{P}=0,001)$ e quinta $(\mathrm{P}=0,005)$. Para $\mathrm{o}$ período $\mathrm{S} 18$, houve diferença significativa $(\mathrm{P}=0,006)$ da primeira com a terceira ordem de parto.

Compararam-se as produções médias nos períodos em uma mesma lactação (Tabela 3) e determinouse diferença significativa entre os períodos, sendo que o intervalo de 8 a 17 semanas (período S8) apresentou maior produção média em todas as ordens de partos; seguido das 18 a 27 semanas, com uma redução e, após os demais intervalos (1 a 7) e (>28), não houve diferença significativa entre eles.

Tabela 3. Médias de produção leiteira (L) de acordo com o período da lactação e a ordem de lactação.

\begin{tabular}{|c|c|c|c|c|c|}
\hline \multirow[t]{2}{*}{ Período de lactação } & \multicolumn{5}{|c|}{ Ordem de Parto } \\
\hline & 1 & 2 & 3 & 4 & 5 \\
\hline 1 a 7 semanas & $1,482^{c}$ & $1,737^{\mathrm{c}}$ & $2,043^{c}$ & $1,738^{c}$ & $1,855^{\mathrm{c}}$ \\
\hline 8 a 17 semanas & $2,878^{a}$ & $3,388^{a}$ & $3,753^{\mathrm{a}}$ & $3,626^{\mathrm{a}}$ & $3,792^{\mathrm{a}}$ \\
\hline 18 a 27 semanas & $2,318^{b}$ & $2,528^{b}$ & $2,817^{b}$ & $2,672^{\mathrm{b}}$ & $2,768^{b}$ \\
\hline$\geq 28$ semanas & $1,703^{\mathrm{c}}$ & $1,701^{\mathrm{c}}$ & $1,774^{\mathrm{c}}$ & $1,803^{\mathrm{c}}$ & $1,639^{\mathrm{c}}$ \\
\hline
\end{tabular}

Letras diferentes na mesma coluna indicam que as são estatisticamente diferentes $(\alpha=0,05)$;

Também Carneiro et al. (2017) observaram diferença no volume de leite produzido entre as fases da lactação em cabras da raça Anglonubiana no semiárido Paraibano. Contudo, Silva et al. (2009) não identificaram efeito significativo $(\mathrm{P}>0,05)$ da ordem de parto sobre a produção de leite de 51 cabras de diferentes raças no Rio Grande do Norte. Os autores concluíram que a raça influencia na produção de leite, embora tenham determinado menor produção média de leite em cabras Saanen $(1,22 \mathrm{~kg} / \mathrm{dia})$ do que o observado no presente estudo. Vale ressaltar que, no plantel analisado no presente estudo, o produtor vinha realizando seleção dos animais que compunham o rebanho considerando o volume de leite produzido e a persistência de lactação, tendo em vista ser esta uma unidade produtiva na qual o leite caprino era a principal atividade pecuária e financeira.

A eficiência produtiva da pecuária leiteira é, em parte, determinada pela eficiência reprodutiva. Entre os parâmetros que permitem avaliar a eficiência reprodutiva e produtiva de um rebanho, destacam-se a idade ao primeiro parto, o intervalo de partos, o período de gestação, a produção de leite e a duração da lactação (Soares Filho et al., 2001).

A unidade produtiva analisada, para manter a produção de leite constante o ano todo, lançava mão de indução do estro. Isto porque cabras são conhecidas por sua estacionalidade reprodutiva, ou seja, marcante influência quanto às variações do fotoperíodo (Fonseca, 2014; Soares Filho et al., 2001). Neste sentido, a possibilidade de se manipular a reprodução de caprinos e ovinos abre oportunidades interessantes para a maximização da exploração destes animais e uso de tecnologias que, inclusive, podem permitir a identificação e multiplicação de genótipos superiores (Fonseca, 2014).

Para verificar o efeito da época do ano na produção leiteira, as cabras de terceira ordem de parto (maior média de produção leiteira) foram analisadas segundo o período de parição (outono e primavera). Verificou-se que as cabras que iniciam a lactação na primavera apresentam maior produção no pico de 
lactação, seguida por queda no volume de leite. Por outro lado, as cabras que tem a lactação com início no outono, apresentam menor volume de leite no pico, mas a produção se mantém constante (Figura 3).

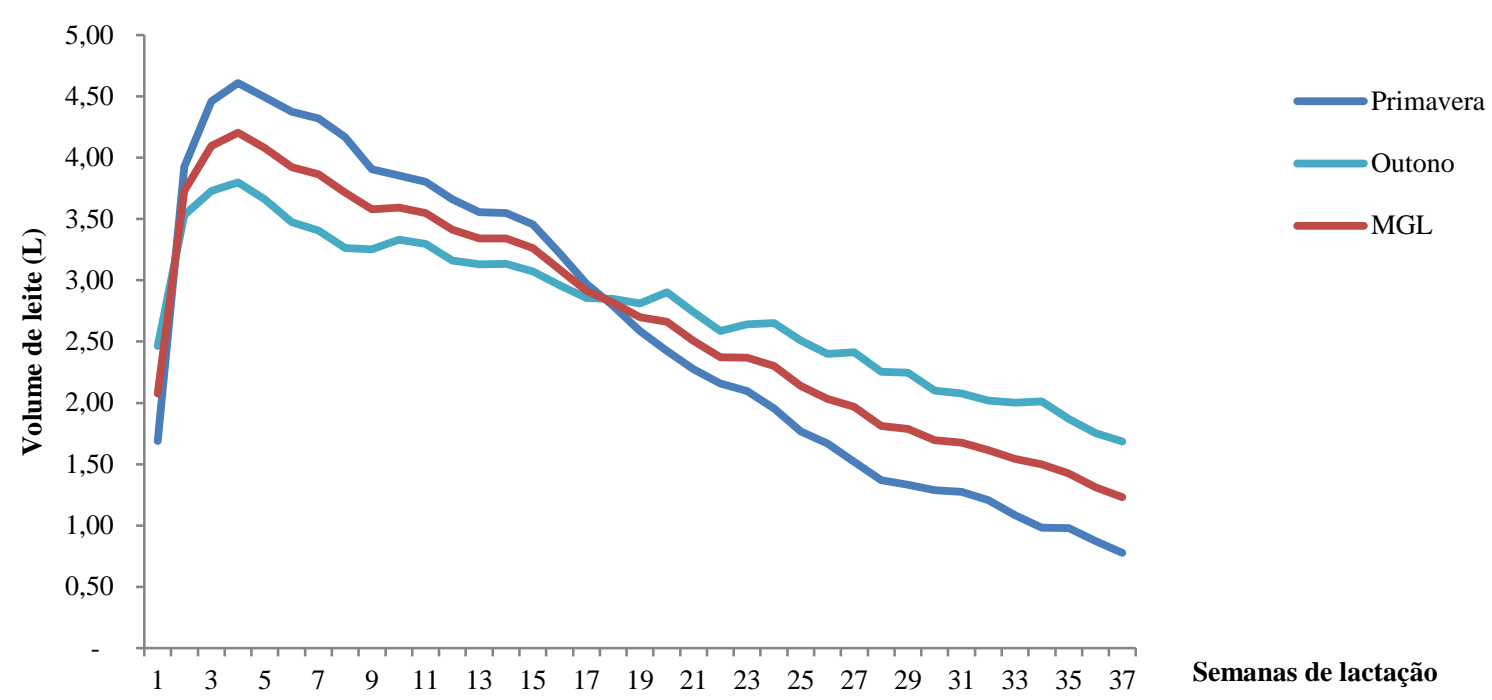

Figura 3. Curva de lactação geral média da terceira ordem de parto, segundo a época de parição (outono e primavera) e curva média geral de lactação (MGL) no período.

A época de parição influenciou o volume de leite, com produção total média de 734,45 L em partos ocorridos na estação do Outono (fevereiro, março) e 680,37 L na primavera (setembro, outubro), em 37 semanas de lactação. A época do parto exerce influência sobre a produção inicial, o pico máximo de produção e a persistência da lactação (Sotillo \& Méndez, 1994).

Diferentemente, no Distrito Federal (Soares Filho et al., 2001), foi determinado que somente a raça influenciou significativamente $(\mathrm{P}<0,05)$ a produção de leite total e, entre os fatores estudados (capril, raça, mês do parto e sexo da cria), nenhum influenciou o período de gestação e a duração da lactação. No estudo, a duração da lactação para cabras paridas em fevereiro (282,64 dias) foi levemente maior do que nas cabras com parição em setembro (268,3 dias). Já, no Semiárido paraibano, foi determinado que a estação de parição influenciasse $(\mathrm{P}<0,05)$ a produção de leite, mas não a duração de lactação (Carneiro et al., 2017).

Esta diferença nos resultados dos autores com os observados no presente estudo podem ser decorrentes das diferenças climáticas regionais, uma vez que na região Sul as estações são bem definidas quanto à disponibilidade de forragens, incidência de chuvas e temperatura. Em São Franciso de Paula, o clima é subtropical $\mathrm{Cfb}$, segundo a classificação do clima de köppen, onde os verões são brandos e úmidos e os invernos relativamente úmidos e frios (Prefeitura Municipal, 2020).

Esta diferença pode, ainda, está associada à oferta de alimentos, uma vez que Zambom et al. (2005) comprovaram que as relações volumoso: concentrado, com diferentes níveis energéticos, influenciam o dia de pico e a produção de leite no pico de lactação. Portanto, rações com maiores níveis energéticos proporcionam maior produção de leite no pico de lactação e retardam o pico de lactação, acarretando maior produção de leite.

A redução de aporte nutritivo às cabras provoca diminuição na produção leiteira (Sotillo \& Méndez, 1994) existindo correlação positiva entre energia ingerida e produção de leite $(r=0,75)$ nas primeiras oito semanas de lactação. Já, temperaturas elevadas reduzem o apetite e, consequentemente, a produção de leite. Este fator poderia explicar a queda brusca na produção leiteira das fêmeas paridas na primavera, coincidente com o mês de fevereiro, demonstrado na Figura 3.

\section{Referências}

Carneiro, W. P., Ramos, J. P. F., Pimenta Filho, E. C., Carvalho, J. E. C., \& Moura, J. F. P. (2017). Avaliação produtiva e reprodutiva de caprinos leiteiros no Semiárido paraibano. Revista Científica de Produção Animal, 18(1), 18-25. 
Fonseca, M. V. (2014). Persistência de lactação e composição do leite de cabras Saanen alimentadas com rações formuladas por diferentes comitês [Dissertações de Mestrado - Universidade Federal de Minas Gerais]. http://hdl.handle.net/1843/BUBD-BCDJAP

Gil, A. C. (2008). Métodos e técnicas de pesquisa social. 6. ed. Ediitora Atlas SA.

Prefeitura Municipal. (2020). Prefeitura Municipal de São Francisco de Paula. https://www.saofranciscodepaula.rs.gov.br/

Rangel, A. H. N., Pereira, T. I. C., Albuquerque Neto, M. C., Medeiros, H. R., Araújo, V. M., Novais, L. P., Abrantes, M. R., \& Lima Júnior, D. M. (2012). Produção e qualidade do leite de cabras de torneios leiteiros. Arquivos Do Instituto Biológico, 79(2), 145-151. https://doi.org/10.1590/S180816572012000200001

Santos, C. M. S., \& Santana, A. F. (2011). Produção de leite e duração da lactação de cabras da raça Pardo-alpina no município de Amélia Rodrigues-BA. PUBVET, 5, Art-1157.

Silva, V. N., Rangel, A. H. N., Braga, A. P., Maia, M. S., \& Medeiros, H. R. (2009). Influência da raça, ordem e ano de parto sobre a produção de leite caprino. Acta Veterinaria Brasilica, 3(4), 146-150.

Soares Filho, G., McManus, C., \& Mariante, A. S. (2001). Fatores genéticos e ambientais que influenciam algumas características de reprodução e produção de leite em cabras no Distrito Federal. Revista Brasileira de Zootecnia, 30(1), 133-140. https://doi.org/10.1590/S1516-35982001000100020

Sotillo, A. Q., \& Méndez, M. L. H. (1994). La Leche de cabra. Universidad de Murcia. https://books.google.com.br/books?id=C6L1TSKJJQUC

Zambom, M. A., Alcalde, C. R., Martins, E. N., Santos, G. T., Macedo, F., Horst, J. A., \& Veiga, D. R. (2005). Lactation curve and milk quality of Saanen goats fed diets with different forage: Concentrate ratios. Curva de Lactação e Qualidade Do Leite de Cabras Saanen Recebendo Rações Com Diferentes Relações Volumoso: Concentrado, 34(6 SUPPL.), 2515-2521. http://www.scopus.com/inward/record.url?eid=2-s2.033645027537\&partnerID=40\&md5=4ea467c535f471b50df1987f55feffdd.

\section{Histórico do artigo:}

Recebido: 15 de setembro de 2020 Aprovado: 20 de outubro de 2020. Disponível online: 29 de janeiro de 2021.
Licenciamento: Este artigoé publicado na modalidade Acesso Aberto sob a licença Creative Commons Atribuição 4.0 (CC-BY 4.0), a qual permite uso irrestrito, distribuição, reprodução em qualquer meio, desde que o autor e a fonte sejam devidamente creditados. 